\title{
Tratamento químico superficial e metalização de ABS, PVC e blendas de PVC/ABS
}

\section{Chemical surface treatment and metallization of $A B S$, PVC and PVC/ABS blends}

\author{
Ana Paula Kurek', Marta Elisa Rosso Dotto ${ }^{2}$, Noeli Sellin ${ }^{3}$ e Pedro Henrique Hermes de Araújo ${ }^{1}$ \\ ${ }^{1}$ Departamento de Engenharia Química e Engenharia de Alimentos, \\ Universidade Federal de Santa Catarina - UFSC, Florianópolis, SC, Brasil \\ ${ }^{2}$ Departamento de Física, Universidade Federal de Santa Catarina - UFSC, Florianópolis, SC, Brasil \\ ${ }_{3}^{3}$ Programa de Mestrado em Engenharia de Processos, Universidade da Região de Joinville - UNIVILLE, \\ Joinville, SC, Brasil \\ *pedro.h.araujo@ufsc.br
}

\begin{abstract}
Resumo
Visando à substituição do ABS em peças cromadas, amostras de PVC e blendas de PVC/ABS, na razão mássica de 20/80, 40/60 e 60/40, foram submetidas ao pré-tratamento em solução sulfocrômica sob diferentes condições de concentração, tempo e temperatura e sendo em seguida cromadas. As modificações na superfície das peças após o condicionamento foram analisadas por microscopia eletrônica de varredura, microscopia de força atômica e rugosidade. A qualidade da deposição metálica foi avaliada por inspeção visual e teste de adesão. Os resultados mostraram que, aumentando a concentração de PVC nas peças necessitou-se de condições operacionais mais agressivas, tais como maiores temperaturas de banho, tempo de imersão e concentração de solução sulfocrômica para que ocorresse a adesão da camada metálica. De todas as condições testadas com a solução condicionante sulfocrômica no tratamento das peças de PVC e blendas PVC/ABS de 20/80 e 40/60, a concentração de 350 g/L de ácido crômico e 400 g/L de ácido sulfúrico, temperatura de $70^{\circ} \mathrm{C}$ e tempo de imersão de 15 minutos, ocasionou deposição do metal em toda a superfície das peças, as quais foram aprovadas nos testes de adesão e corrosão.
\end{abstract}

Palavras-chave: cromagem, ABS, PVC, blendas PVC/ABS.

\section{Abstract}

To replace ABS in plated objects, samples of PVC and blends of PVC/ABS, in mass ratio of 20/80, 40/60 and 60/40, were subjected to step-conditioning (etching) in sulfochromic solution, under different conditions of concentration, time and temperature, being plated in sequence. Modifications of the surface of the samples after conditioning were analyzed by scanning electron microscopy, atomic force microscopy and roughness. The quality of metal deposition was evaluated by visual inspection and adhesion tests. Results show that increasing the amount of PVC in the blend required more aggressive operational conditions to promote metallic adhesion; higher temperature, immersion time and sulfochromic solution concentration. From all tested conditions with the sulfochromic solution for the treatment of PVC, and 20/80 and 40/60 PVC/ABS blend samples, the concentration of $350 \mathrm{~g} \mathrm{~L}^{-1}$ of chromic acid and $400 \mathrm{~g} \mathrm{~L}^{-1}$ of sulfuric acid at $70^{\circ} \mathrm{C}$ and immersion time of 15 minutes, resulted in the deposition of metal layers in all evaluated specimens. These were approved in adhesion and corrosion tests.

Keywords: plating, ABS, PVC, PVC/ABS blends.

\section{Introdução}

A galvanoplastia em polímeros é um tipo de tratamento de superfície muito utilizado, e ao contrário do que ocorre com os metais, nos quais a camada metálica depositada tem uma utilidade anticorrosiva, em polímeros, possui finalidade estética e decorativa. Para uma adequada adesão desta camada, a superfície da peça precisa ser modificada por processos químicos e/ou físicos que ocasionam alterações na morfologia e estrutura da superfície do polímero por meio de formação de microcavidades com aumento na rugosidade e aspereza, que proporcionam maior interação metal-polímero e favorecem a adesão da camada metálica ${ }^{[1]}$. O processo mais empregado pelas indústrias galvânicas para a modificação da superfície de peças em ABS é por imersão delas em banho condicionador composto por solução sulfocrômica (ácido crômico e ácido sulfúrico), na etapa de pré-tratamento do processo de cromagem, ocasionando alterações na superfície, 
que favorecem a adesão da camada metálica ${ }^{[2]}$. O terpolímero ABS (acrilonitrila-butadieno-estireno) é o polímero mais empregado na fabricação de peças cromadas com função decorativa, principalmente devido à sua composição e estrutura química. No processo de galvanoplastia, tem uma contribuição significativa, representando $50 \%$ do consumo total, outros tipos de polímeros podem ser cromados, seguindo-se processo semelhante ao do ABS, os mais conhecidos e já em uso são o polipropileno, policarbonato e poliacetal. Não há relatos na literatura sobre a metalização de peças de poli(cloreto de vinila) (PVC), apesar da grande versatilidade e aplicabilidade deste polímero ${ }^{[3]}$. Mediante a incorporação de aditivos, o PVC pode ter suas características alteradas dentro de um amplo espectro de propriedades em função da aplicação final, variando sua forma desde rígido à extremamente flexível, passando por aplicações que vão desde tubos e perfís rígidos para uso na construção civil até brinquedos e laminados flexíveis para acondicionamento de sangue e plasma. Rápidas mudanças vêm exigindo das empresas maior racionalização, competitividade e modernização, tudo em busca de produtos com qualidade, menor custo e ecologicamente corretos ${ }^{[4]}$. No processo de galvanoplastia, o poli(cloreto de vinila) (PVC) ou blendas de PVC/ABS podem ser uma alternativa viável para a substituição do ABS aumentando as aplicações do PVC e reduzindo os custos. Sendo assim, este trabalho tem como objetivo o estudo do processo de modificação superficial sob diferentes condições operacionais (concentração de solução sulfocrômica, tempo de imersão e temperatura) e metalização de amostras de PVC puro e das blendas de $\mathrm{PVC} / \mathrm{ABS}$ em diferentes proporções.

\section{Experimental}

\subsection{Preparação do composto de PVC e das blendas de PVC/ABS}

O composto de PVC foi preparado em um misturador da marca Intensivo Mecanoplast ML-9, conforme formulação descrita na Tabela 1.

A resina ABS (marca BASF-GP35) foi desumidificada por $2 \mathrm{~h}$ a $60^{\circ} \mathrm{C}$ e misturada com o composto de PVC na razão mássica de 20/80, 40/60 e 60/40 (PVC/ABS). A mistura foi então alimentada em uma extrusora, marca Miotto, com $30 \mathrm{~mm}$ de diâmetro de rosca. A resina de PVC e a blenda de PVC/ABS foram obtidas em pellets pela Empresa Braskem (São Paulo, SP, Brasil), e transformadas em peças pelo processo de injeção na Empresa Durin Ltda. (Araquari, SC, Brasil).

Tabela 1. Formulação do composto de PVC.

\begin{tabular}{llc}
\hline \multicolumn{1}{c}{ Produto } & \multicolumn{1}{c}{ Função } & $\begin{array}{c}\text { Fração mássica } \\
\text { (\%) }\end{array}$ \\
\hline Norvic SP 700 RA & Resina de PVC K57 & 83,8 \\
Maftosa FE CZ 5023 & Estabilizante Térmico & 4 \\
& Ca/Zn & \\
Paraloid K1120 ND & Modificador de Fluxo & 1 \\
Paraloid KM 334 & Modificador de Impacto & 6 \\
CaCO $_{3}$ Precipitado & Carga Orgânica & 5 \\
Ácido Esteárico & Lubrificante Externo & 0,2 \\
\hline
\end{tabular}

\subsection{Modificação da superfície de PVC e das blendas de $P V C / A B S$}

As peças de PVC e das blendas de PVC/ABS foram submetidas ao pré-tratamento em diferentes concentrações da solução sulfocrômica, sob agitação constante, em diferentes temperaturas $\left(50,60\right.$ e $\left.70^{\circ} \mathrm{C}\right)$ e tempos de imersão $(5,10$ e 15 minutos). Todos os testes foram realizados em duplicata. Após a etapa de condicionamento, as amostras foram enxaguadas vigorosamente em água corrente e submetidas às etapas convencionais empregadas no processo industrial de galvanização (banhos) para a deposição da camada metálica (neutralização, ativação, aceleração, deposição química de níquel, deposição eletrolítica de cobre, níquel e cromo). A cromagem das amostras foi realizada na empresa Sigmacrom Indústria e Comércio de Artefatos Plásticos Ltda, Araquari, SC, Brasil.

\subsection{Caracterização por inspeção visual e teste de adesão após o processo de cromagem}

Inspeção visual - A avaliação da deposição da camada metálica das amostras cromadas foi realizada por inspeção visual, nas amostras de PVC e das blendas PVC/ABS, analisando-se a presença de defeitos, como deposição incompleta do metal e peças danificadas ${ }^{[5]}$.

Adesão metálica - Para os testes de adesão da camada metálica depositada a peça cromada foi fixada em um dispositivo e serrada manualmente, a partir do verso da peça revestida, evitando descascamento nas superfícies de corte. Este teste foi realizado somente nas amostras aprovadas na inspeção visual[ ${ }^{[6]}$.

\subsection{Avaliação das modificações na superfície das amostras}

Para a avaliação por MEV, AFM e rugosidade foram selecionadas as amostras imersas na solução condicionante sulfocrômica com concentração de $350 \mathrm{~g} / \mathrm{L}$ de ácido crômico e $400 \mathrm{~g} / \mathrm{L}$ de ácido sulfúrico, com tempos de imersão de 5 e 15 minutos e a $70^{\circ} \mathrm{C}$.

Microscopia eletrônica de varredura (MEV) - As amostras foram cortadas em pedaços pequenos, metalizadas com ouro para tornarem-se eletricamente condutoras e então analisadas em microscópio eletrônico de varredura (JEOL JSM-6390LV), com filamento de tungstênio, voltagem de aceleração de $15 \mathrm{kV}$ e ampliação de 3000 vezes, do Laboratório Central de Microscopia Eletrônica (LCME) da UFSC.

Microscopia de força atômica (AFM) e rugosidade - As amostras foram posicionadas no equipamento modelo Nanosurf Flex AFM, do Laboratório de Sistemas Anisotrópicos - Departamento de Física - CFM/UFSC, operando em modo intermitente (Tapping Mode), ponta modelo TAP 190, com raio menor que $10 \mathrm{~nm}$, frequência de ressonância de 190 kHz, constante de mola de 48 N/m e velocidade de varredura de 1 linha/s. As imagens obtidas foram tratadas usando o programa WSxM e a partir deste foram gerados os perfis de rugosidade e calculadas a rugosidade média e a amplitude máxima da rugosidade. 


\section{Resultados e Discussão}

Os resultados da qualidade da deposição metálica nas amostras de ABS puro, PVC puro e nas blendas de $\mathrm{PVC} / \mathrm{ABS}$ condicionadas com soluções contendo diferentes concentrações de ácido crômico no banho condicionador, sob diferentes tempos de imersão e temperaturas, estão apresentados na Tabela 2 .

Na solução contendo $300 \mathrm{~g} / \mathrm{L}$ de ácido crômico, todas as amostras em PVC puro foram reprovadas no teste de aderência, e em algumas amostras houve falha já na deposição da primeira camada, ou seja, camada de níquel químico. As amostras testadas em temperatura de $70^{\circ} \mathrm{C}$, com tempo de imersão de 15 minutos com concentrações de $350 \mathrm{~g} / \mathrm{L}$ e $400 \mathrm{~g} / \mathrm{L}$ foram as únicas amostras aprovadas. Analisando os resultados, observa-se que as concentrações utilizadas de ácido crômico apresentaram resultados positivos a partir de $350 \mathrm{~g} / \mathrm{L}$, valor próximo ao da concentração padrão empregada industrialmente para peças em ABS puro (400 g/L). Para as blendas de PVC/ABS 20/80 as amostras foram aprovadas quando submetidas a tempos, temperaturas e concentrações de solução sulfocrômica mais elevadas, conforme mostrado na Tabela 2. Neste caso, verificou-se que a temperatura e a concentração tem grande influência sobre o ataque químico ocasionado, pois as amostras imersas em condições mais severas apresentaram resultados positivos.
Na Figura 1, são apresentadas as imagens de MEV das superfícies das amostras de ABS puro, das blendas de PVC/ABS e do PVC puro, antes do condicionamento em solução sulfocrômica ( $350 \mathrm{~g} / \mathrm{L}$ de ácido crômico e $400 \mathrm{~g} / \mathrm{L}$ de ácido sulfúrico), com 5 e 15 minutos de tratamento e a $70^{\circ} \mathrm{C}$.

As amostras de ABS sem condicionamento químico apresentam estrutura bastante uniforme, podendo-se visualizar as linhas provenientes de imperfeições no molde de injeção das peças. Na superfície das amostras de PVC e das blendas PVC/ABS, observa-se a presença de grânulos na superfície relacionados aos aditivos usados na formulação do PVC. As amostras de ABS puro e da blenda com maior teor deste material (PVC/ABS 20/80), Figuras 1 (3b), foram mais susceptíveis ao ataque pela solução sulfocrômica do que as amostras de PVC puro, em tempo de tratamento de 5 minutos, verificando-se alterações na morfologia da superfície, como poros com formatos irregulares, reentrâncias e microvales. No entanto, somente a amostra de ABS puro foi aprovada no teste de adesão para esse tempo de condicionamento. A solução sulfocrômica ocasiona remoção dos componentes do terpolímero ABS, principalmente, do butadieno da superfície, enquanto que o PVC é mais resistente quimicamente. Tempo de tratamento maior, de 15 minutos, tornou mais significativas as alterações na superfície observadas nas amostras descritas anteriormente, Figuras 1 (3c), com

Tabela 2. Avaliação da qualidade da deposição metálica nas amostras de ABS puro, blendas PVC/ABS e PVC puro condicionadas em soluções de ácido sulfúrico e ácido crômico.

\begin{tabular}{|c|c|c|c|c|c|c|c|}
\hline & & & & & Adesão & & \\
\hline Solução & $\begin{array}{l}\text { Tempo } \\
\text { (min.) }\end{array}$ & Temp. $\left({ }^{\circ} \mathrm{C}\right)$ & ABS & $\begin{array}{l}\text { BLENDA PVC/ } \\
\text { ABS 20/80 }\end{array}$ & $\begin{array}{c}\text { BLENDA PVC/ } \\
\text { ABS 40/60 }\end{array}$ & $\begin{array}{c}\text { BLENDA PVC/ } \\
\text { ABS 60/40 }\end{array}$ & PVC \\
\hline \multirow{9}{*}{$\begin{array}{l}\text { Ácido Crômico } \\
300 \mathrm{~g} / \mathrm{L} \text { Ácido } \\
\text { Sulfúrico } 400 \mathrm{~g} / \mathrm{L}\end{array}$} & 5 & 50 & - & - & - & - & - \\
\hline & 10 & 50 & A & - & - & - & - \\
\hline & 15 & 50 & A & - & - & - & - \\
\hline & 5 & 60 & A & - & - & - & - \\
\hline & 10 & 60 & A & - & - & - & - \\
\hline & 15 & 60 & A & - & - & - & - \\
\hline & 5 & 70 & A & - & - & - & - \\
\hline & 10 & 70 & A & - & - & - & - \\
\hline & 15 & 70 & - & - & - & - & - \\
\hline \multirow{9}{*}{$\begin{array}{l}\text { Ácido Crômico } \\
350 \mathrm{~g} / \mathrm{L} \text { Ácido } \\
\text { Sulfúrico } 400 \mathrm{~g} / \mathrm{L}\end{array}$} & 5 & 50 & - & - & -- & - & - \\
\hline & 10 & 50 & A & - & -- & - & - \\
\hline & 15 & 50 & A & - & A & - & - \\
\hline & 5 & 60 & A & - & - & - & - \\
\hline & 10 & 60 & A & - & A & - & - \\
\hline & 15 & 60 & A & - & A & - & - \\
\hline & 5 & 70 & A & $\mathrm{R}$ & $\mathrm{R}$ & - & - \\
\hline & 10 & 70 & A & $\mathrm{R}$ & A & - & - \\
\hline & 15 & 70 & - & A & A & - & A \\
\hline \multirow{9}{*}{$\begin{array}{l}\text { Ácido Crômico } \\
400 \mathrm{~g} / \mathrm{L} \text { Ácido } \\
\text { Sulfúrico } 400 \mathrm{~g} / \mathrm{L}\end{array}$} & 5 & 50 & - & $\mathrm{R}$ & - & - & - \\
\hline & 10 & 50 & A & $\mathrm{R}$ & A & - & - \\
\hline & 15 & 50 & A & A & A & - & $\mathrm{R}$ \\
\hline & 5 & 60 & A & $\mathrm{R}$ & A & - & - \\
\hline & 10 & 60 & A & $\mathrm{R}$ & A & - & - \\
\hline & 15 & 60 & A & A & A & - & - \\
\hline & 5 & 70 & A & A & A & - & - \\
\hline & 10 & 70 & A & A & A & - & - \\
\hline & 15 & 70 & - & A & - & - & A \\
\hline
\end{tabular}

A: Aprovado; R: Reprovado; - :Teste não realizado por não haver passado na inspeção visual. 
aprovação no teste de adesão metálica da blenda PVC/ABS 20/80. Nas amostras de PVC puro e de blendas com maiores teores deste material, Figuras 2 (4 e 5 (c)), o tratamento por
15 minutos ocasionou diferentes alterações na superfície, como aparência menos rugosa, presença de poros mais definidos e ondulações. Neste caso, a solução sulfocrômica

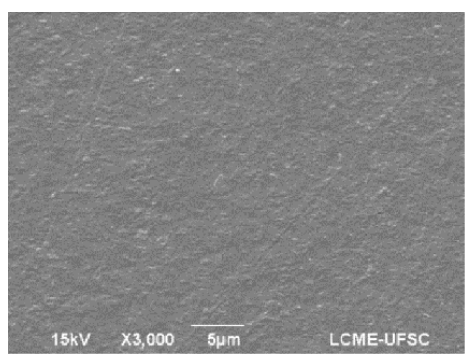

(1a)

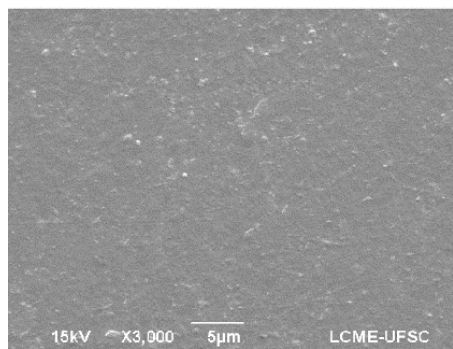

(2a)

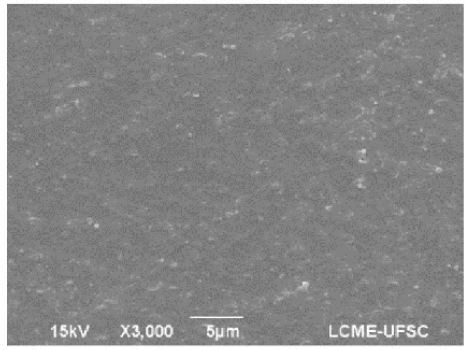

(3a)

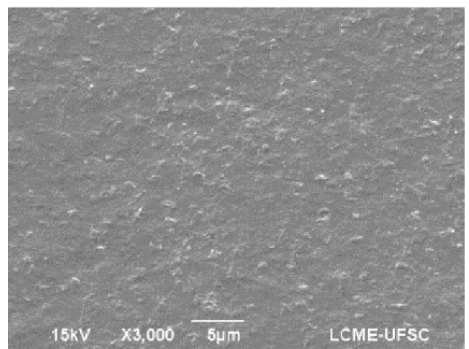

(4a)

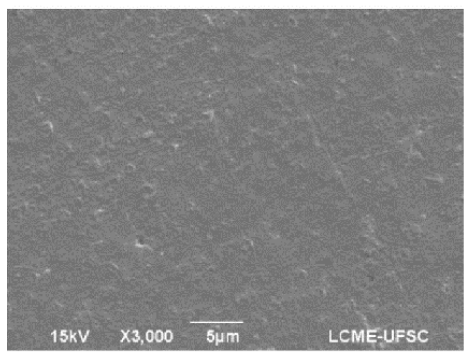

(5a)

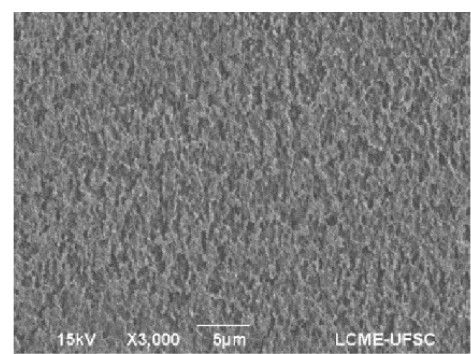

(1b)

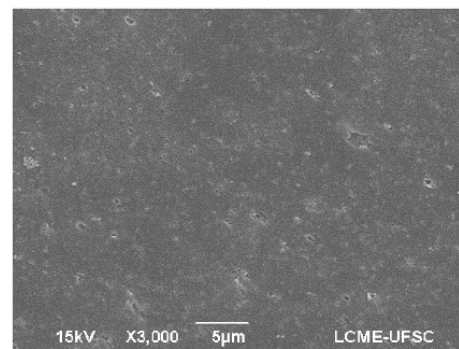

(2b)

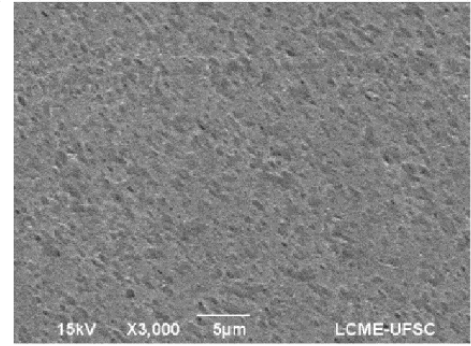

(3b)

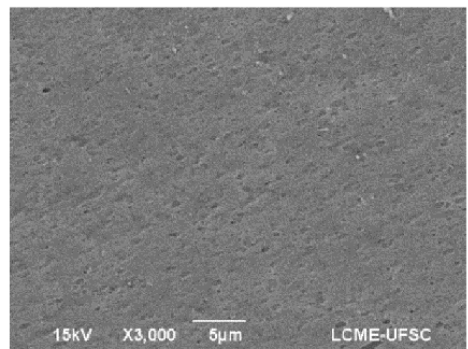

(4b)

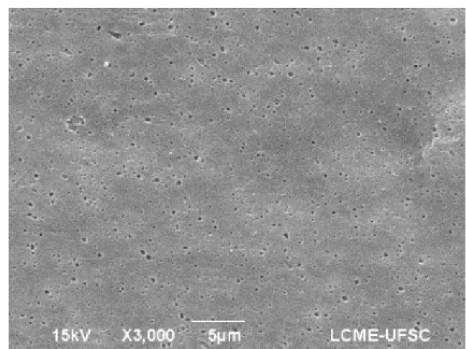

(5b)

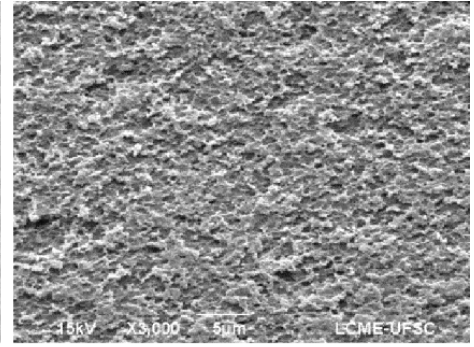

(1c)

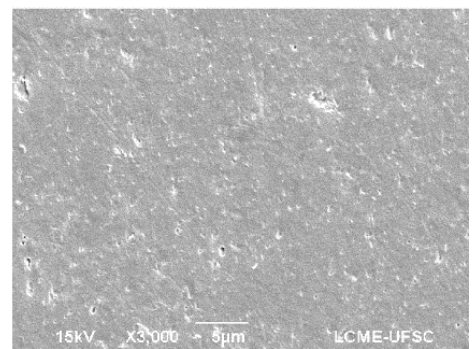

$(2 \mathrm{c})$

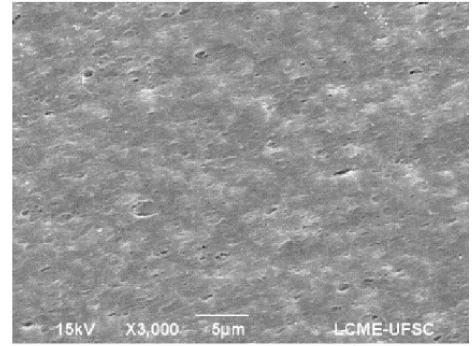

$(3 c)$

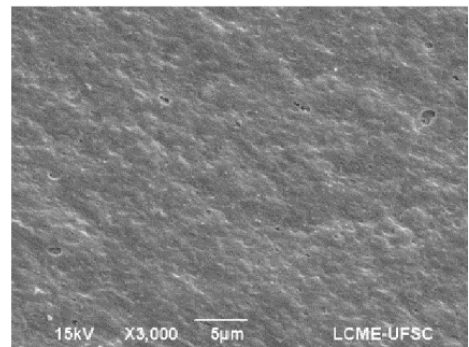

$(4 c)$

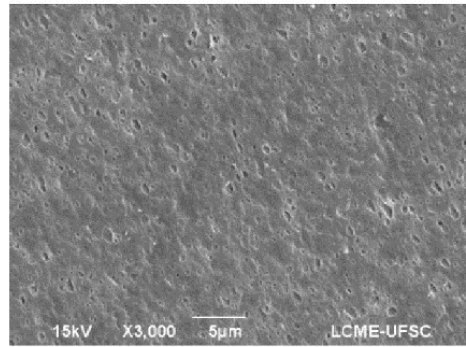

$(5 \mathrm{c})$

Figura 1. Micrografia de MEV da superfície das amostras de ABS puro (1), PVC puro (2), blenda PVC/ABS 20/80 (3), blenda PVC/ABS 40/60 (4) e blenda PVC/ABS 60/40 (5), sendo (a) sem condicionamento, (b) com tempo de imersão de 5 min e (c) com tempo de imersão de 15 min, em solução sulfocrômica com concentração de $350 \mathrm{~g} / \mathrm{L}$ de ácido crômico e $400 \mathrm{~g} / \mathrm{L}$ de ácido sulfúrico e temperatura de $70{ }^{\circ} \mathrm{C}$. 

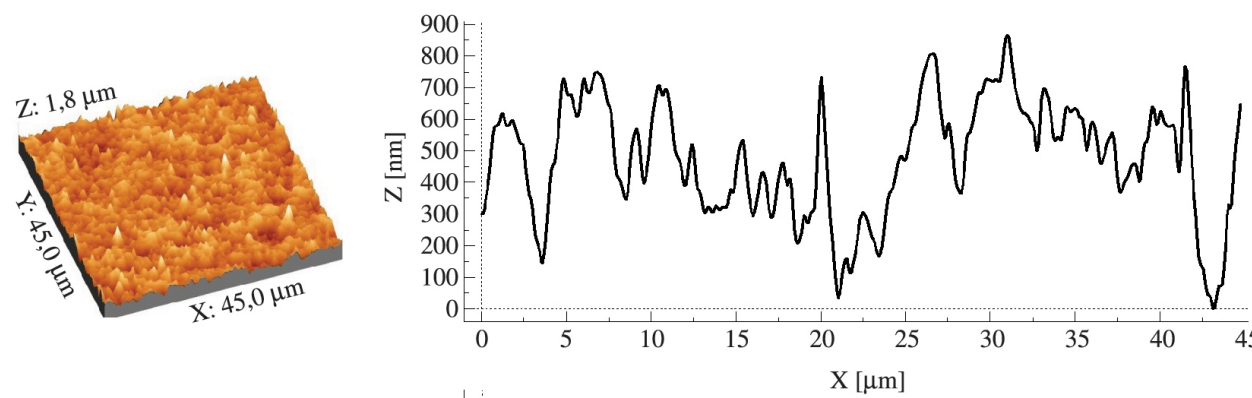

(a)
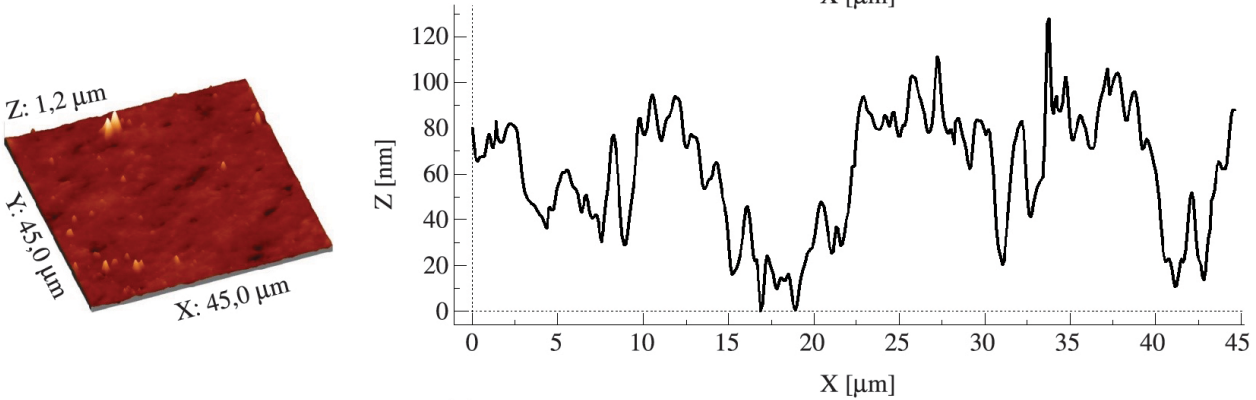

(b)
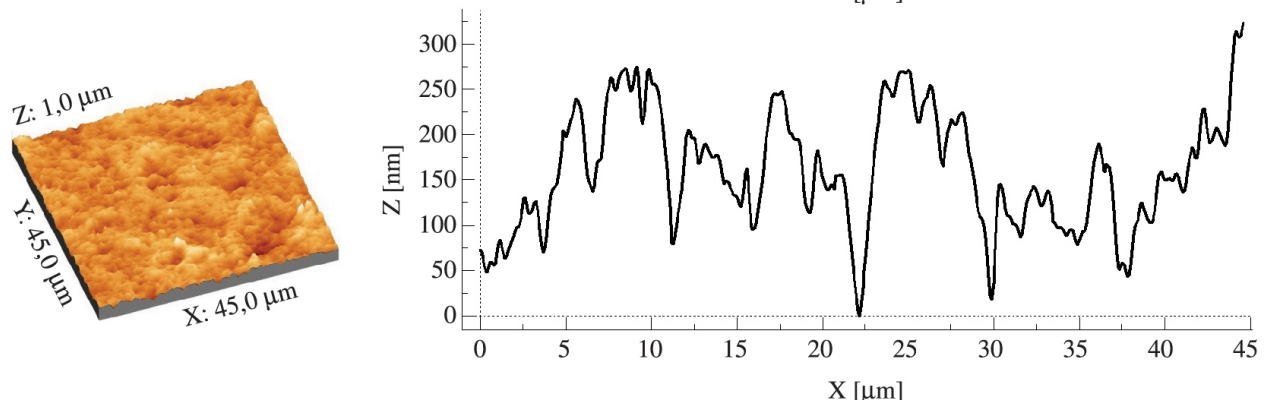

(c)
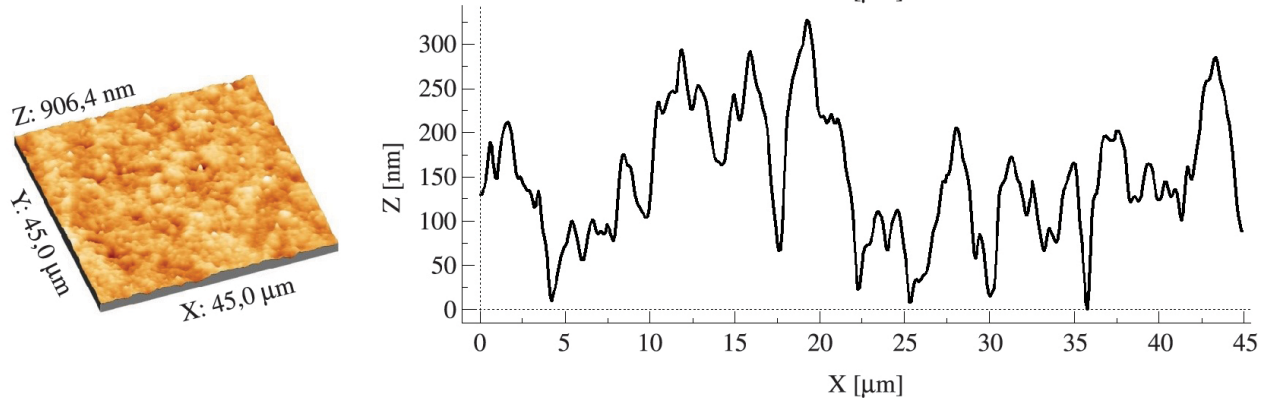

(d)

Figura 2. Imagens de AFM e gráficos do perfil da rugosidade da superfície das amostras de ABS puro (a), PVC puro (b), blenda PVC/ABS 40/60 (c) e blenda PVC/ABS 60/40 (d) condicionadas em solução sulfocrômica com concentração de $350 \mathrm{~g} / \mathrm{L}$ de ácido crômico e $400 \mathrm{~g} / \mathrm{L}$ de ácido sulfúrico, tempo de imersão de 15 min e temperatura de $70{ }^{\circ} \mathrm{C}$.

promoveu ataque menos agressivo na superfície, porém, foi suficiente para promover a adesão metálica nas amostras de PVC puro e da blenda PVC/ABS 40/60.

As alterações observadas após o condicionamento químico influenciaram diretamente na deposição metálica e mostraram ser dependentes das condições operacionais (temperatura e tempo) empregadas. Em estudos de metalização de ABS submetido a soluções sulfocrômicas, observaram alterações na rugosidade superficial e adesão satisfatória da camada metálica para amostras submetidas a temperaturas que variaram de 20 a $70{ }^{\circ} \mathrm{C}^{[7]}$. Porém, conforme mostrado na Tabela 2, para os testes realizados com ácido crômico, verifica-se que sob temperaturas baixas, de $50{ }^{\circ} \mathrm{C}$, as amostras foram reprovadas, provavelmente não ocorreu alteração significativa da morfologia da superfície. Estudos mostraram que a degradação térmica acelerada do $\mathrm{ABS}$ sem condicionamento a temperaturas maiores que $80^{\circ} \mathrm{C}$ e observaram que nestas condições ocorre a formação de microporos na superfície da amostra devido à degradação ocasionada ${ }^{[8]}$. Temperaturas maiores que $70{ }^{\circ} \mathrm{C}$ dificilmente são usadas, pois podem ocasionar deformação das peças durante o tratamento. $\mathrm{O}$ tempo de imersão no condicionamento também tem bastante influência no grau de modificação da superfície, geralmente, 5 a 15 minutos, são suficientes para formar um grande 
Tabela 3. Rugosidade RMS (média quadrática) da superfície das amostras de ABS puro, blendas PVC/ABS e PVC puro antes do condicionamento e após condicionamento em solução condicionante sulfocrômica, sob tempos de imersão de 5 e 15 minutos e temperatura $70^{\circ} \mathrm{C}$.

\begin{tabular}{lccccc}
\hline & ABS & $\begin{array}{c}\text { Blenda PVC/ } \\
\text { ABS 20/80 }\end{array}$ & $\begin{array}{c}\text { Blenda PVC/ } \\
\text { ABS 40/60 }\end{array}$ & Blenda PVC/ABS 60/40 & PVC \\
\hline \multicolumn{5}{c}{ Rugosidade RMS (nm) } \\
\hline Sem condicionamento & 44,03 & 40,94 & 67,03 & 60,73 & 38,46 \\
5 minutos & 231,70 & 103,9 & 87,83 & 63,55 & 39,44 \\
15 minutos & 168,90 & 118,9 & 79,8 & 80,40 & 50,2 \\
\hline
\end{tabular}

número de pequenas cavidades na superfície da peça. Se o tempo for muito prolongado, em alguns casos, a quantidade de poros formados pode ultrapassar a profundidade de 1 a $2 \mu \mathrm{m}$ na superfície da amostra e prejudicar a adesão $0^{[9-11]}$. $\mathrm{E}$, quando usado em aplicação industrial tempos maiores que 15 minutos podem reduzir a produtividade, tornando inviável o processo.

Os resultados da rugosidade média das amostras de ABS puro, PVC puro e blendas de PVC/ABS condicionadas em solução sulfocrômica, sob tempos de imersão de 5 e 15 minutos e temperatura $70^{\circ} \mathrm{C}$, estão apresentados na Tabela 3 .

As amostras de PVC puro sem tratamento apresentam baixa rugosidade, de $38,46 \mathrm{~nm}$, quando comparadas com as amostras de ABS e das blendas também sem tratamento. De modo geral, ocorre um aumento da rugosidade com o aumento do tempo de tratamento em solução sulfocrômica, com valores mais altos para as amostras com maiores concentrações de ABS, evidenciando que o ABS é mais susceptível ao ataque pela solução sulfocrômica que o PVC, conforme verificado pelos resultados de MEV.

Na Figura 2, são apresentadas as imagens de AFM e gráficos do perfil da rugosidade das superfícies das amostras de ABS, PVC e blendas de PVC/ABS 40/60 e $60 / 40$, submetidas ao tratamento em solução sulfocrômica contendo $350 \mathrm{~g} / \mathrm{L}$ de ácido crômico e $400 \mathrm{~g} / \mathrm{L}$ de ácido sulfúrico, por 15 minutos e a $70^{\circ} \mathrm{C}$.

Observa-se na imagem de AFM e do gráfico da Figura 2a, que o ABS condicionado por 15 minutos apresenta picos agudos (alta amplitude da rugosidade, $\mathrm{Z}$ ), poros, cavidades e reentrâncias em toda a superfície, com rugosidade RMS de 168, nm. A amostra de PVC, Figura 2b, após o condicionamento, apresentou superfície mais ondulada, com poros, porém menos rugosa que a de $\mathrm{ABS}$ e com baixa amplitude, evidenciando a resistência do $\mathrm{PVC}$ ao ataque pela solução sulfocrômica. As amostras das blendas de PVC/ABS 40/60 e 60/40 condicionadas, Figuras 2c, d, apresentaram alterações semelhantes na morfologia, com picos mais arredondados e amplitude da rugosidade variando entre a da amostra de PVC e ABS puros. Um aumento na concentração de ABS na blenda torna a superfície mais susceptível ao ataque pela solução sulfocrômica. Para a modificação de superfícies poliméricas, a escolha do meio e das condições reacionais deve ser avaliada após o ataque na superfície do polímero, pois o objetivo não é promover degradação e sim ocasionar alterações na morfologia que favoreçam a adesão das camadas metálicas, como ancoramento mecânico ${ }^{[12-14]}$. As amostras tratadas com 15 minutos apresentaram superfícies com maior rugosidade e uma topografia mais favorável a adesão da camada metálica devido a maior presença de poros, cavidades e reentrâncias distribuídas na superfície do polímero. $\mathrm{O}$ ataque ácido afeta preferencialmente os meros de butadieno contidos na fase borrachosa do ABS, extraindo esta fase e deixando espaços vazios na superfície polimérica. Os resultados mostraram que outros polímeros, como o PVC, também podem sofrer ataque ácido, porém, em condições mais severas, tais como maior tempo de reação, temperatura e concentração de ácido. Além disso, durante o ataque ácido a superfície se torna mais polar e hidrofílica devido a sulfonação da superfície polimérica o que aumenta sua molhabilidade, favorecendo a ativação da superfície e, consequentemente, o ancoramento metálico na superfície do material.

\section{Conclusão}

Os resultados mostraram que a adesão das camadas metálicas nas peças avaliadas mostrou ser dependente da quantidade de PVC na amostra e nas condições operacionais empregadas no banho condicionador. Aumentando a concentração de PVC na amostra necessitou-se de condições operacionais mais agressivas, tais como maiores temperaturas de banho, tempo de imersão e concentração de solução sulfocrômica para que ocorresse a adesão da camada metálica, possibilitando inclusive a metalização de peças de PVC puro. No entanto, as mesmas condições agressivas, que possibilitaram a cromagem do PVC, que é mais estável quimicamente que o ABS, impossibilitaram uma adesão adequada da camada metálica sobre peças de ABS puro.

\section{Agradecimentos}

Às empresas brasileiras Braskem pelo fornecimento da blenda e do PVC, Durin pelo uso do processo de injeção e Sigmacrom pelos laboratórios e processo de cromagem. Ao Laboratório Central de Microscopia Eletrônica da UFSC (LCME) pelas imagens de microscopia eletrônica de varredura.

\section{Referências}

1. Teixeira, L. A., \& Santini, M. C. (2005). Surface conditioning of ABS for metallization without the use of chromium baths. Journal of Materials Processing Technology, 170(1-2), 37-41. http://dx.doi.org/10.1016/j.jmatprotec.2005.04.075.

2. Kurek, A. P., Sellin, N., \& Gelsleichter, M. (2009). Redução e substituição do ácido crômico na etapa de condicionamento de ABS para metalização. Polímeros: Ciência e Tecnologia, 19(3), 248-254. http://dx.doi.org/10.1590/S0104-14282009000300014.

3. Nunes, L. R., Rodolfo, A. Jr, \& Ormanji, W. (2006). Tecnologia do PVC. São Paulo: Braskem.

4. Bos, A., \& Fels, C. (2012). Metalização direta de plásticos ABS e ABS-PC. Revista Tratamento de Superfície, 31(172), 68-71. Retrieved from http://www.abts.org.br/revista-visualizar. asp?id=11\&edicao $=172$ 
5. Associação Brasileira de Normas Técnicas. (1983). NBR 8094: Material metálico revestido e não-revestido - Corrosão por exposição à névoa salina. Rio de Janeiro: ABNT.

6. DaimlerChrysler. (2002). Norma DBL-8465: especificações para fornecimento de peças de plástico com revestimentos metálicos eletrodepositados. São Paulo: Mercedes Benz do Brasil.

7. Begun, Z., Goosey, T. M., Gravez, E. J., Poole, A., \& Singh, A. (2004). US. US Patent No 6790334 B2. USA.

8. Tiganis, B. E., Burn, L. S., Davis, P., \& Hill, A. J. (2002). Thermal degradation oacrynolitrile-butadiene-styrene (ABS) blends. Polymer Degradation \& Stability, 76(3), 425-434. http://dx.doi.org/10.1016/S0141-3910(02)00045-9.

9. Kato, K. (1967). ABS mouldings for electroplating - an electron microscope study. Polymer, 8, 33-39. http://dx.doi. org/10.1016/0032-3861(67)90005-5.

10. Courduvelis, C. I. (1986). US. Patent No WO 1986000085 A1. USA.

11. Tang, X., Cao, M., Bi, C., Yan, L., \& Zhang, B. (2008). Research on a new surface activation process for electroless plating on
ABS plastic. Materials Letters, 62(6-7), 1089-1091. http:// dx.doi.org/10.1016/j.matlet.2007.07.055.

12. Dotto, M. E. R. (2003). Universalidade e leis de escalas em amostras de sílicio atacadas quimicamente (Tese de Doutorado). Universidade Federal de Santa Catarina, Trindade.

13. Mauler, R. S., Galland-Barrera, G., Samios, D., Guaragna, F., Crossetti, G., \& Gobi, D. (1992). Estudo da reação de quebra de polímeros com H5I06 para obtenção de polímeros com terminações funcionais. Polímeros: Ciência e Tecnologia, 2(1) 21-24. Retrieved from http://www.revistapolimeros.org. br/articles/view/id/515c6c9e1 ef1 fae740000534

14. Alonso, J. G., Molina, E. C., Muniz, E. C., Rubira, A. F., \& Carvalho, G. M. (2005). Modificação química de poli(tereftalato de etileno) pós-consumo por reação com ácido sulfúrico: estrutura e propriedades. Polímeros: Ciência e Tecnologia, 15(1), 27-32. http://dx.doi.org/10.1590/S0104-14282005000100008.

Enviado: Jul. 14, 2014

Revisado: Dez. 17, 2014

Aceito: Jan. 07, 2015 